\title{
Renal Vein Thrombosis
}

National Cancer Institute

\section{Source}

National Cancer Institute. Renal Vein Thrombosis. NCI Thesaurus. Code C99042.

The formation of a thrombus in the renal vein. 